\title{
Misinterpret of a unique clinical presentation named "Soo ul qinya" in Traditional Persian medicine with "Anemia"
}

\author{
Review Article
}

\section{Mojdeh Pourhosseini ${ }^{1}$, Fatemeh Nojavan ${ }^{2}$, Abolfazl Mohammadbeigi $^{3}$, Hossein Moradi $^{2 *}$}

1. PhD Student of Iranian Traditional Medicine, Qom University of Medical Sciences, Qom, Iran

2. Department of Iranian Traditional Medicine, Qom University of Medical Sciences, Qom, Iran

3. Neurosciences Research Centre, Department of Epidemiology,

Qom University of Medical Sciences, Qom, Iran

\begin{abstract}
In Traditional Persian medicine resources, soo ul qinya is one of the liver diseases that also named as predropsy. The search for articles published suggests that the soo ul qinya disease is equivalent to the anemia without any explanation. The aim of the present article is to verify this claim. After critical appraisal of books and articles, the required information was collected and these materials were contrasted accurately, they were compiled in the form of an article. Soo ul qinya is a difficulty in liver function and appearing weakness in it as liver could not doing its normal function and not producing good and desirable materials for feeding the body and Anemia refers to a low level of hemoglobin in the blood, which can be caused by very low levels of red blood cells or hemoglobin deficiency in blood cells. Etiology and signs and symptoms of soo ul qinya and anemia are sometimes similar and sometimes different but full compatibility between two diseases not found. Anemia is defined as a hemoglobin deficiency that can be caused by very low levels of red blood cells or hemoglobin deficiency in blood cells. However, soo ul qinya is defined as the inability of the liver to produce blood that deserves supplying foods to the cells of the body. We know that the transfer of food components like proteins, carbohydrates, fats, and micronutrients occurs by the plasma, not by hemoglobin and soo ul qiny a cannot be equivalent to anemia.
\end{abstract}

Keywords: Soo ul qinya, SUQ, Anemia, Traditional Persian medicine .

\section{Introduction}

Traditional Persian medicine (TPM) is one of the oldest sciences that includes valuable and unique concepts that description them can raise the world's knowledge. (1)Reviving this ancient science depends on description the hidden concepts which could be found in traditional medicine's sources.

One of these unique and operational concepts is "soo ul qinya" Which is a clinical manifestation of liver disease, in which the skin is swollen and discolored. $(2,3,4)$

The search for articles published in journals and databases suggests that the word soo ul qinya, which is one of the major diseases in Traditional Persian medicine (TPM), is equivalent to the anemia.(5-7)

Unfortunately, this disease is misunderstanding today and conflicted with anemia. Treatments for current diseases are affected by this mistake.

soo ul qinya (SUQ) is a difficulty in liver function and appearing weakness in it as liver cannot do its normal function and not producing good and desirable materials for feeding the body. In Iranian traditional medicine's valid resources, soo ul qinya is

\section{*Corresponding Author:}

\section{Hossein Moradi,}

Department of Iranian Traditional Medicine,

Qom University of Medical Sciences,

Qom, Iran.

Email id:poormojde4@gmail.com one of the liver diseases that also named as pre dropsy. $(3,4)$

There are very few articles that have now been published on soo ul qinya in valid international journals or indexed in scientific databases are very limited. In some other articles, the name of the disease is not used in the title of the article, but in the body of the text. Nevertheless, these articles have almost one common thing. In most cases, soo ul qinya is considered as an equivalent to anemia without any explanation from the beginning.(5-7) where does such equation originate from and when did it begin? Why?

The aim of the present article is to verify the misinterpretation of a unique clinical presentation named "soo ul qinya " in traditional Persian medicine with "anemia".

\section{Materials and Methods}

The present study is a review-descriptive study. First, 906 books and research projects among credible texts of traditional medicine that have been registered on Noor Islamic software were checked exactly.(8) The Islamic and traditional medicine librarian software contains the most important and valuable books in traditional medicine. This software is contained of $80 \%$ of original references of Iranian traditional medicine.

First, the title of all books and their contents was reviewed and also the article titles were checked. Then, the related books with article's object is read and notetaken manually and checked with initial texts again. Moreover, " soo ul qinya " and "su ul qinya" and "pre 
dropsy" and "anemia" keywords was used for strategic searches in international scientific databases include PubMed, Scopus and Since Direct, web of sciences. In addition, these keywords were used in searching Iranian article in Iranian databases such as Scientific Information Database (SID), Iranmedex and Irandoc. Because our studying object is one of the hepatic diseases, studying all of the traditional medicine books and articles in Noor comprehensive Islamic medicine software, the pathology books and articles were selected and rest of books were eliminated. As all of the therapy books precede hepatic diseases as section of the most important body diseases, these books were assessed critically. In this step, collection of information about " soo ul qinya" disease began specifically. After that, taking note was begun to study more precise with " soo ul qinya keyword in therapy and pathology books of first to $14^{\text {th }}$ A.H century.

All of the related books and articles were choose and the contents of books and the abstract of all related articles were checked critically. At first the complete text of " soo ul qinya" disease section was studied in all selected books and then the relations between books and this article's object is checked precisely. Then all of these points are checked with another researcher and the duplications and citations from the original references was excluding. The critical appraisal of books and articles are checked with two main researchers of research team by stretchered checklist. Finally, all of the verified points and up to main researcher opinion are used.

Exclusion criteria in this study were including that the object of book is not related to pathology or is not preceded to " soo ul qinya" disease. Moreover, since this disease has not been known before 610 A.D, all of the books out of this time frame were eliminated. Inclusion criteria were pathology books from first to $14^{\text {th }}$ A.H century or the $7^{\text {th }}$ to $19^{\text {th }}$ A.D century with " soo $\boldsymbol{u l}$ qinya " object. In addition, all related articles were searched to last day of March 2018.

We also made an email contact with the authors of some of the soo ul qinya articles, and asked them about the reason for equating this word with anemia. When the required information were collected and these materials were contrasted accurately, they were compiled in the form of an article.

\section{Results}

The results of this study described at 4 different level including definition, signs and symptoms and Etiology of soo ul qinya and anemia as well as findings of literature review.

Soo ul qinya (SUQ) definition: Avicenna said that "Soo ul qinya occurs due to decaying state of the liver and its weakness, which leads to "Istisqa" disease and also called temperament corruption."(4) Seyed Esmaeil Jorjani(9) NAjib-Uddin Samarghandi(10), Mohammad Azam Nazem Jahan(3), and other Traditional Persian medicine (TPM) scholars present similar description. In fact, " soo ul qinya" is a clinical manifestation of the underlying liver disease that occurs with swelling and pallor and some other symptoms.

Anemia definition: In the original sources of new medicine has been described that Anemia refers to a low level of hemoglobin in the blood, which can be caused by very low levels of red blood cells or hemoglobin deficiency in blood cells.(11) There is also a consensus in new scientific articles that anemia diagnostic criteria are based on one's hemoglobin concentration, which is affected by the age, place of residence, and gender.(12-16)

\section{The most important signs and symptoms of soo ul qinya:}

- Skin and face discoloration or pallor: The initial symptoms of soo ul qinya include face and body skin pale and discoloration to white or yellow.(17)

- Edema: Swelling appears on the eyelid, face, hands and feet.(18)

- Gastric digestion disorder: In soo ul qinya digestion is impaired.(4)

- Borborygmus and gas: Borborygmus and gas are made in the abdomen.(18)

- Change in appetite: Increased appetite is sometimes seen.(19)

- Changes in stool disposal and defecation disturbance: Occasionally, stool becomes soft sometimes gets stiff.(3)

- Irregular sleep-wake rhythm: Individuals have sometimes deep sleep and occasional suffer from insomnia.(20)

- Reduced urination and sweating volume: The volume of urine and sweat decreases.(18)

- Delay in wound healing: When a wound is made in the body, it hardly heals.(4)

- Gum itching and wounds: In many cases, the gum becomes itchy and it is sometimes injured.(3)

- Heaviness and fatigue: A sense of heaviness and weakness is felt in the body.(21)

- Other rare symptoms: lip injury, thirst, weakness of the legs, leg wound, anorexia, white and diluted urine, and slowness of the body movements. $(3,4,9,10,17-21)$

\section{The most important signs and symptoms of anemia:}

The symptoms of anemia referred to in classical medicine include: Fatigue, pallor, a decreased exercise capacity are common symptoms in all stages of the anemia, cheilosis, and spoon nails are seen in the advanced stages of iron-deficiency anemia.(22)

Table 1 showed the signs and symptoms factors of soo ul qinya and anemia.

\section{Etiology of soo ul qinya:}

Eight main category of etiology can be describing for soo ul qinya including liver factors, Lifestyle-related factors, Gastric factors, Splenic factors, Intestinal factors, Uterine factors, Kidney and bladder factors and Age factors.

- Liver factors: Among the causes of soo ul qinya, liver factors have a special place. In fact, it can be said that the liver factors are the most important causes of this disease and ultimately all pathogens for soo ul qinya and Istisqa (Dropsy) must go through the path of liver weakness. Both hepatic temperament disturbances 
and the impaired composition of a member can lead to soo ul qinya and Istisqa. $(3,4)$

- Lifestyle-related factors: Another group of causes introduced as causes of soo ul qinya include lifestylerelated factors, which include six main health factors according to the traditional medicine; namely food and drinks, climates, sleep and awakening, movements and rest, mental states, retention and evacuation.

- Edible foods: Anyone who suddenly gets too much cold temper food (Based on Iranian traditional medicine) will be at risk of soo ul qinya. "Strongly avoid over-eating and eating hard-to-digest foods such as fresh fish and dairy products, fats, and sesame oil, starch, sweet bread, cookies, and noodles in case of soo ul qinya." $(23,3)$

- Climates: Soo ul qinya sometimes occurs due to the effect of external cold on the members and occasionally due to air contamination.(3)

- Evacuation: Evacuation in traditional medicine means ejection of the waste matter from the body generally or in a specific way.(24) soo ul qinya is sometimes caused due to the stoppage and delay of the usual bleeding of the body, such as menses and hemorrhoids, and sometimes due to the severe blood loss in menses and hemorrhoids. Excessive matter ejection in the form of diarrhea, urine or sweat weakens the whole body, especially the liver, which in turn is associated with the risk of soo ul qinya. $(3,4)$

- Extreme physical and mental movements: The known causes of soo ul qinya include extreme physical and mental movements. Excessive intercourse, like physical and emotional movements, is cited as the causes of this disease.(21)

- Gastric factors: Gastric causes are one of the most important causes of soo ul qinya. Sometimes soo ul qinya is caused by a gastric dysfunction and weakness.(25)

- Splenic factors: Splenic factors include spleen enlargement, stiff or soft or warm splenic swelling, and large amounts of black bile discharge from the spleen or inability to absorb the black bile produced in the liver. $(4,25)$

- Intestinal factors: In addition to cold or warm intestinal temperament issues, severe intestinal pains and long cramps, scratches of the intestinal wall, long disposal of tangible or intangible blood cause liver weakness and soo ul qinya.(4)

- Uterine factors: Amenorrhea or excessive uterus bleeding or frequent and prolonged uterus pain can ultimately lead to the liver weakness and soo $\boldsymbol{u l}$ qinya. $(3,4)$

- Kidney and bladder factors: TPM believes that kidneys are responsible for the removal of bloodrelated excessive moisture from the body, and excrete excessive wastes at the same time. Any disruption in this disposal system will lead to many complications for the general health of the body, one of the most important of which is the occurrence of soo ul qinya disease. Temperament problems such as excessive coldness or warming of the kidneys and member disorders, such as cramps or severe swelling, can lead to kidney malfunction and a lack of proper absorption of haptic moisture.(10)

- Age factors: According to TPM, aging is an accumulation of moisture in the body physiologically, and these conditions can create the grounds for moisture-related diseases such as soo ul qinya. Aging is also the cause of the liver weakness, which in turn leads to soo ul qinya.(21)

The prolonged fever and febrile diseases, prolonged disease and pain, some drugs, and some other less frequent causes are also reported in the etiology of the disease, but we will not discuss them.

\section{Etiology of anemia:}

There are different types of anemia in the classical medicine, and their etiology and pathogenesis are classified as follows:

- Iron deficiency or other causes of decreased hemoglobin production: Low iron consumption and low blood production due to menstruation are the most common causes of iron-deficiency anemia. Anemia due to inflammation or acute or chronic infection and Anemia due to chronic diseases especially in people with chronic kidney disease as well as Anemia due to nutritional and endocrine deficiencies including protein deficiency, B12 deficiency, Folic acid deficiency, Vitamin E deficiency, Vitamin B6 deficiency, Vitamin C deficiency \& Copper deficiency are Other sections of this category.

- Anemia caused by liver diseases: Mild anemia may occur in patients with a variety of chronic liver disease. In this type of anemia, peripheral blood smears may indicate spore and stomatitis cells, and excessive accumulation of cholesterol is observed in the membrane due to lecithin-cholesterol acetyltransferase deficiency. Red cell survival is shortened and EPO production is too insufficient to compensate for anemia.

- Hereditary anemia or anemia due to hemoglobin abnormalities: Thalassemia is a genetic type of anemia that often occurs in Mediterranean people. Sickle cell anemia is a genetic disease that is a form of sticky and hard red blood cells. These cells stick together and reduce or block their blood flow.

- Types of hemolytic anemia: Autoimmune hemolytic anemia that destroys red blood cells and causes anemia. Congenital hemolytic anemia and Acquired hemolytic anemia that caused by toxins, medications, cell destruction, and infections.

- Anemia due to bleeding

- Aplastic anemia: In people with aplastic anemia, the bone marrow does not produce enough blood cells, including red blood cells. Viral infections, side effects of medicines or autoimmune diseases can lead to aplastic anemia.(22)

Table 2 showed the main and subheading etiology factors of soo ul qinya as well as the different main types of anemia and its subgroups.

\section{Findings of literature review:}

Considering the limited scientific articles on soo 
ul qinya in recent years, the term " soo ul qinya" is generally considered as an equivalent for anemia.(5-7) After reviewing of the sources and references of these articles and sending emails to some of the authors of these articles, the authors stated that this equation was based on existing sources, such as Shar̃ al-Asbāb(10), Tebb-e-Akbari(17) (Akbari medicine), and Ghamoose of canon(26), which used anemia as an equivalent for soo ul qinya. After referring to the available translations and the footnotes of the books mentioned above, we found that most of these references referred to in a later book called Moalejat-e-Vaezi. This book, written in the Urdu language, was not found, despite extensive search in Iranian libraries and traditional medicine colleges and accredited Traditional Persian medicine research centers as well as in person search in Pakistan as a center for Urdu language books.

\section{Discussion}

\section{Comparison of anemia definition in physiological resources and traditional medicine sources:}

According to the definition in Guyton \& Hall's Textbook of Medical Physiology, anemia is defined as a hemoglobin deficiency that can be caused by very low levels of red blood cells or hemoglobin deficiency in blood cells. According to the definition of the same book, the duties of hemoglobin are as the followings:

One of the duties of red blood cells is to transfer hemoglobin, which is responsible for the transfer of oxygen from the lungs to the tissues of the body.(11) However, soo ul qinya is defined as the inability of the liver to produce blood that deserves supplying foods to the cells of the body. There is a fundamental difference between anemia and soo ul qinya in this comparison. Impaired oxygen supply and impaired food supply is the main issue in anemia and soo ul qinya, respectively. The traditional medicine states that one of the food components, that is to say, digestible components, may be air or oxygen, which is also transferred by blood; however, the scope of the word (food) is undoubtedly much broader than oxygen and the impaired oxygen supply can't be completely be considered as equivalent to the impaired food supply. We know that the transfer of food components like proteins, carbohydrates, fats, and micronutrients occurs by the plasma, not by hemoglobin. On the other hand, there are clear equivalents for anemia in Traditional Persian medicine describe this disease using specific definitions.

"atroghia","ghellat-ul-dam","faghr-ul-dam" are terms that are considered as equivalents to for anemia in TPM, $(3,4,10)$ and considering the reasons mentioned above, the word soo ul qinya is not an equivalent to anemia.

\section{Comparison of anemia symptoms in internal medicine resources and traditional medicine resources:}

An important symptom of the soo ul qinya disease includes pallor of the face and body skin. The most commonly diagnosed symptoms of anemia in the conventional medicine include abnormal paleness, white or yellow, and lack of adequate blood supply to the skin. Symptoms such fatigue and decreased exercise capacity are common symptoms of anemia and soo ul qinya, but there is no trace of other symptoms of soo ul qinya in anemia. As you can see, anemia symptoms are only part of the symptoms that may be observed in soo ul qinya, and since hematopoietic agents and anemia treatments are also included as treatments for soo ul qinya, it can be concluded that anemia can be part of soo ul qinya; however, they can't be used interchangeably, and it is thus wrong and non-scientific to use anemia as an equivalent for soo ul qinya. The findings showed that impaired digestion is one of the most important causes of soo ul qinya. In the view of traditional medicine, there are four digestions for food. Since the important product of the second digestion, i.e. the liver digestion, is good and pure blood, and the product of the third digestion, i.e. vascular digestion, is the blood usable for each member, if the amount of such useful and valuable product decreases or undergo quality loses in a way that does not do its function properly in the body, symptoms of "Blood poverty" or anemia gradually occur. However, this is just part of the pathophysiology of soo ul qinya and anemia symptoms accout for just a small fraction of the symptoms of systemic soo ul qinya.

Comparison of anemia etiology in internal medicine resources and Traditional Persian medicine sources: The etiology of anemia also indicates a significant difference between soo ul qinya and anemia. The results of reviewing the causes of soo ul qinya showed that some of the causes of this disease are also seen in some types of anemia. For example, various liver diseases can lead to soo ul qinya. Also, as noted in Harrison's reference book, various liver diseases can be a mild type of hypo proliferative anemia. Also, nutritional problem is one of the causes of soo ul qinya such as excessive consumption of foods that make the liver cool based on the viewpoint of traditional medicine or inappropriate drinking of drinking water. Nutritional deficiencies were also referred to as one of the causes of hypo proliferative anemia. However, comparing these two requires further research. Chronic diseases such as kidney diseases were also included in the etiology of anemia and kidney dysfunction can occur in soo ul qinya, or the presence of acute or chronic infections or inflammation in the body are commonly mentioned in both causes, namely anemia and soo ul qinya. Considering the hemolytic anemia, we also mention the infectious causes or toxins and medications and this etiology is also mentioned for soo ul qinya in traditional medicine books. Bleeding is also one of the common causes of anemia and some types of soo ul qinya. Despite these common aspects, there are many differences in the etiology of the two diseases. Various causes, such as climatic conditions, blood retention in the body, intestinal disorder, uterine disorder, temperament issues, and general overload of the body are present as the causes of soo ul qinya and none of them are seen in the anemia etiology. There are also some types of anemia that are not associated with causes of soo ul qinya, such as hereditary anemia or bone marrow disorders.

\section{Conclusion}

soo ul qinya isn't anemia but the symptoms of anemia Such as pallor and fatigue are part of the soo $\boldsymbol{u l}$ 
qinya symptoms. Because of these similarities, these diseases are confused with each other. The most similarity was observed between signs and symptoms of soo ul qinya and hypo proliferative anemia, although this similarity is not 100 percent, and it cannot be concluded that soo ul qinya a is the same as a hypo proliferative anemia. It is also better to say that hypo proliferative anemia is a complication of soo ul qinya.

soo ul qinya is a nutritional problem and anemia is a problem in oxygenation. As mentioned the scope of the word (food) is undoubtedly much broader than oxygen and the impaired oxygen supply can't be completely being considered as equivalent to the impaired food supply. We know that the transfer of food components like proteins, carbohydrates, fats, and micronutrients occurs by the plasma, not by hemoglobin.

\section{Acknowledgments:}

This article is an introduction to the $\mathrm{PhD}$ thesis entitled "Development and Psychometric properties of diagnostic tool of Soo ul qinya (pre Dropsy) in Traditional Persian medicine" (27)

Source of Funding: Qom University of Medical Sciences

Acknowledgement: The authors are very grateful for Qom University of Medical Sciences for supporting this work.

\section{References}

1. Nazem E. Tabiat (Nature). 1st Edition. Tehran; Abej Press; 2011. 16p.

2. Samarghandi N. Sharh-ul-Asbab \& Alamat. Kermani N, editor. Qom; Jalaleddin Press; 2008. $34 \mathrm{p}$

3. Nazem Jahan MA. Exir-e A'zam. 2rd Edition. Tehran; Iran University of medical science; 2008. 66-77p.

4. Avicenna. The canon of medicine. 1st Edition. Beirut; Institute Dare Ehya al-Toras; 2005. 209$217 \mathrm{p}$

5. Anzar A. Faqr-Ud-Dam (Anaemia) an Age- Old Malady in Unani Medicine -An Overview. International journal of Pharmamedix India. 2014; 2(4); 782-789.

6. Noman Khan F, Abid M, Ansari A. CLINICAL TRIAL TO EVALUATE THE EFFICACY \& SAFETY OF UNANI FORMULATION "TAB DAMWI" IN SOO-UL-QINYA (HYPOCHROMIC ANEMIA). EUROPEAN JOURNAL OF PHARMACEUTICAL AND MEDICAL RESEARCH. 2016; 3(9); 217-222

7. Ali khan A, SHubrina S, Javaid R. MATERNAL AND CHILD HEALTH - AN APPROACH THROUGH UNANI SYSTEM OF MEDICINE. International Journal of anaalytical, pharmaceutical and Biomedical Sciences. 2013; 2(3); 16-18

8. Comprehensive Library of Medicine $1 / 5$. Computer Research Center of Islamic Sciences; 2015.

9. Jorjani A. Zakhireh Kharazmshcahi. Daneshpajoh M, Afshar E, editors. 1st Edition. Tehran; Tehran University Publishing; 1973. 164-171p

10. Samarghandi N. Sharh-ul-Asbab \& Alamat.
Kermani N, editor. Qom; Jalaleddin Press; 2008. 44-34p

11. Arthur C. Guyton, John E. Hall. Textbook f medical physiology.13 ed. Publishing Services Manager; Patricia Tannian; 2013. 569p.

12. Tandon R, Jain A, Malhotra P. Management of Iron Deficiency Anemia in Pregnancy in India. Indian J Hematol Blood Transfus. 2018 Apr; 34(2); 204215. Epub 2018 Mar 14.

13. Yasemin Işık Balc1, Aysun Karabulut, Dolunay Gürses, İbrahim Ethem Çövüt. Prevalence and Risk Factors of Anemia among Adolescents in Denizli, Turkey. Iran J Pediatr. 2012 Mar; 22(1); 77-81.

14. Neil A. Zakai, Ronit Katz, Calvin Hirsch, et al. A Prospective Study of Anemia Status, Hemoglobin Concentration, and Mortality in an Elderly Cohort the Cardiovascular Health Study. Arch Intern Med. 2005; 165(19); 2214-2220

15. Chandyo RK, Ulak M, Adhikari RK, Sommerfelt $\mathrm{H}$, Strand TA. Prevalence of Iron Deficiency and Anemia among Young Children with Acute Diarrhea in Bhaktapur, Nepal. Healthcare (Basel). 2015 Jul 21; 3(3); 593-606. doi: 0.3390/ healthcare3030593

16. Menon MP, Yoon SS. Prevalence and Factors Associated with Anemia among Children Under 5 Years of Age--Uganda, 2009. Am J Trop Med Hyg. 2015 Sep; 93(3); 521-6. doi: 10.4269/ajtmh.150102. Epub 2015 Jun 8.

17. Arzani MA. Teb-e-Akbari [Akbari's Medicine]. Ehya Teb e Tabiee O, editor. Qom; Jalaleddin Press; 2008. 726-727p.

18. Razi B. Kholasat al-Tajarob. 1st Edition. Tehran; Iran University of medical science; 2003. 316p.

19. Razi MZ. Al-Havi. 1st Edition. Beirut; Institute Dare EhyaAl-toras; 2001. 532-572p

20. Ghaderi A. Fosool Al-Aaraaz. 1st Edition. Tehran; Iran University of medical science; 2008. 202p

21. Ibn Solom Halabi S. GHayat-al-Etghan fi Tadbir badan-al-Ensan. Tehran; Iran University of medical science; 2009. 412p.

22. Jameson, et al. Harrison's Principles of Internal Medicine 20th Edition PDF 2018 FREE Download [Direct Link]. 126-130p.

23. Akhawayni R. Hedayat al Motaallemin fi Teb. Matini J, editor. 2rd Edition. Mashhad; Mashhad University Press; 1992. 449-450p

24. Heravi M. Bahr al-Javaher. 1st ed. Qom; Jalal alDin; 2008. 222p.

25. Abdollah M. Tohfe-e KHani. Tehran; Iran University of medical science; 2004. 467-472p

26. Abdolhamid H, et al. Ghamoose of canon. Tehran; Iran University of medical science; Manuscript. 456p.

27. Pourhosseini M. Development and Psychometric properties of diagnostic tool of Soo ul qinya (pre Dropsy) in Traditional Persian medicine [dissertation]. Iran; Qom University of Medical Sciences; 2018. 


\section{International Journal of Ayurvedic Medicine, 2019, 10(2), 130-135}

Table 1: Signs and symptoms factors of soo ul qinya and anemia

\begin{tabular}{|c|c|}
\hline Soo ul qinya & Anemia referred to the classical medicine. \\
\hline Skin and face discoloration or pallor & Fatigue \\
\hline Edema & Pallor \\
\hline Gastric digestion disorder & A decreased exercise capacity \\
\hline Borborygmus and gas & Cheilosis \\
\hline Change in appetite & Spoon nails \\
\hline Changes in stool disposal & \\
\hline Irregular sleep-wake rhythm & \\
\hline Reduced urination and sweating volume & \\
\hline Delay in wound healing & \\
\hline Gum itching and wounds & \\
\hline Heaviness and Fatigue & \\
\hline Other rare symptoms & \\
\hline
\end{tabular}

Table 2: The etiology factors of soo ul qinya and anemia

\begin{tabular}{|c|c|c|c|}
\hline \multicolumn{2}{|c|}{ Soo ul qinya } & \multicolumn{2}{|c|}{ Anemia } \\
\hline Main causes & Subheading causes & $\begin{array}{l}\text { Different main types } \\
\text { of anemia in the clas- } \\
\text { sical medicine }\end{array}$ & Subgroups of anemia \\
\hline liver factors & & $\begin{array}{l}\text { Iron deficiency or other } \\
\text { causes of decreased hemo- } \\
\text { globin production }\end{array}$ & \\
\hline \multirow{5}{*}{$\begin{array}{l}\text { Lifestyle-related fac- } \\
\text { tors }\end{array}$} & & & Iron-deficiency anemia \\
\hline & Edible foods & & $\begin{array}{l}\text { Anemia due to inflam- } \\
\text { mation or acute or } \\
\text { chronic infection }\end{array}$ \\
\hline & Climates & & $\begin{array}{l}\text { Anemia due to chronic } \\
\text { diseases }\end{array}$ \\
\hline & Evacuation & & $\begin{array}{l}\text { Anemia due to nutri- } \\
\text { tional and endocrine } \\
\text { deficiencies }\end{array}$ \\
\hline & $\begin{array}{l}\text { Extreme physical and } \\
\text { mental movements }\end{array}$ & & $\begin{array}{l}\text { Anemia caused by liver } \\
\text { diseases }\end{array}$ \\
\hline Gastric factors & & $\begin{array}{c}\text { Hereditary anemia or ane- } \\
\text { mia due to hemoglobin } \\
\text { abnormalities }\end{array}$ & \\
\hline Splenic factors & & & Thalassemia \\
\hline Intestinal factors & & & Sickle cell anemia \\
\hline Uterine factors & & Hemolytic anemia & \\
\hline $\begin{array}{l}\text { Kidney and bladder } \\
\text { factors }\end{array}$ & & & $\begin{array}{l}\text { Autoimmune hemolytic } \\
\text { anemia }\end{array}$ \\
\hline \multirow[t]{4}{*}{ Age } & & & $\begin{array}{l}\text { Congenital hemolytic } \\
\text { anemia }\end{array}$ \\
\hline & & & $\begin{array}{l}\text { Acquired congenital } \\
\text { hemolytic anemia }\end{array}$ \\
\hline & & Anemia due to bleeding & \\
\hline & & Aplastic anemia & \\
\hline
\end{tabular}

